\title{
Optimum Additive Composition to Minimize Fat in Functional Goat Meat Nuggets: A Healthy Red Meat Functional Food
}

\author{
Tahreem Kausar $^{1}$, Mohd Adnan Kausar ${ }^{2}$, Saif Khan ${ }^{3}$, Shafiul Haque ${ }^{4}$ (D) and Z. R. Azaz Ahmad Azad ${ }^{1,5, *(D)}$ \\ 1 Department of Food Technology, School of Interdisciplinary Sciences and Technology (SIST), Jamia Hamdard, \\ New Delhi 110062, India; tahreemkausar.sch@jamiahamdard.ac.in \\ 2 Department of Biochemistry, College of Medicine, University of Ha'il, Ha'il 2440, Saudi Arabia; \\ ma.kausar@uoh.edu.sa \\ 3 Department of Basic Dental and Medical Sciences, College of Dentistry, University of Ha'il, \\ Ha'il 2440, Saudi Arabia; saifkhan.bio@gmail.com \\ 4 Research and Scientific Studies Unit, College of Nursing and Allied Health Sciences, Jazan University, \\ Jazan 2097, Saudi Arabia; shafiul.haque@hotmail.com \\ 5 Department of Post Harvest Engineering and Technology, Aligarh Muslim University, Aligarh 202001, India \\ * Correspondence: zrazad@jamiahamdard.ac.in or zrazad@gmail.com
}

Citation: Kausar, T.; Kausar, M.A.; Khan, S.; Haque, S.; Azad, Z.R.A.A. Optimum Additive Composition to Minimize Fat in Functional Goat Meat Nuggets: A Healthy Red Meat Functional Food. Processes 2021, 9, 475. https://doi.org/10.3390/ pr9030475

Academic Editor: Sanghyun Lee

Received: 31 January 2021

Accepted: 1 March 2021

Published: 7 March 2021

Publisher's Note: MDPI stays neutral with regard to jurisdictional claims in published maps and institutional affiliations.

Copyright: (c) 2021 by the authors. Licensee MDPI, Basel, Switzerland. This article is an open access article distributed under the terms and conditions of the Creative Commons Attribution (CC BY) license (https:/ / creativecommons.org/licenses/by/ $4.0 /)$.

\begin{abstract}
Optimally designed functional foods are considered the most important part of a balanced and healthy diet. Goat meat nuggets, an otherwise healthy option, are packed with undesirable saturated and unsaturated fats. The present work suggests an optimal functional formulation to reduce the surplus fat content of goat meat nuggets by adding two optimally calculated functional ingredients, namely, fenugreek leaves (FL) and psyllium husk (PH). Response surface optimization was performed to determine the optimal content of the functional ingredients (FL and PH), resulting in minimum fat content without affecting the overall acceptability (OA) and other properties representing the taste and texture (e.g., ash content, $\mathrm{pH}$, crude fiber content, and moisture content) of the nuggets. Functional additives at optimum levels successfully reduced the fat content of the weight-conserved nuggets by almost 39\% compared with the control nuggets. Minimal and acceptable effects were observed regarding $\mathrm{OA}$ and other properties representative of the taste and texture of the nuggets. An optimally designed, fat-attenuated goat meat nugget formulation is therefore prescribed, which complies with the nutritional standards of a balanced diet.
\end{abstract}

Keywords: nuggets; fenugreek leaves; psyllium husk; optimization; fat content

\section{Introduction}

Over the last few decades, people have begun to prefer healthy and convenient foods, such as ready-to-eat or precooked foods, due to busier lifestyles, leading to an effective change in eating habits. The consumption of meat and meat products is continuously increasing worldwide because of their ideal source of soluble minerals, vitamins, essential fats, amino acids, and many other nutrients with a specific function in the body. Compared to plant sources, meat contains a rich source of iron and vitamin B, especially vitamin B12, which is absent in plant foods [1]. The consumption of meat leads to satiety, and meat is a nutritious and ready-to-eat, convenient food.

Goat meat is the most popular option among meat from ruminant species and is universally accepted by all communities in India without religious and social taboos [2]. Goat meat is a darker red in color than lamb and beef and has a coarser texture with a different flavor and aroma [3]. It is leaner than beef and lamb and also contains less marbling and subcutaneous fat $[4,5]$. The main drawback of processed meat products is that they contain a high level of saturated fatty acids and cholesterol but no fiber, properties which are associated with several chronic diseases, such as cardiovascular disease, various types of cancer, and obesity [6]. 
The major drawback of red meat is the lack of dietary fiber; hence, regular consumption is associated with an increased level of cholesterol, sodium, fat, saturated fatty acids, and calories, but low fiber intake $[7,8]$. Consumption of red-meat-related products is unhealthy and subjects the consumer to saturated fats and synthetic antioxidants that result in several degenerative diseases, such as obesity, hypertension, diabetes, high cholesterol levels, and cardiovascular disease $[9,10]$.

In 2010, the US Department of Health and Human Services (USDHHS) and US Department of Agriculture (USDA) published dietary guidelines demonstrating how saturated fats and associated levels of low-density lipoprotein (LDL) cholesterol are directly proportional to the risk of cardiovascular disease (CVD) (Dietary Guidelines for Americans 2010). In India, $70 \%$ of colorectal cancer cases are caused by improper diet. Various international studies highlighted the positive association between dietary fat and red meat consumption with colorectal cancer and mortality [11,12]. The US Preventive Services Task Force presented a report calling upon the United States population to decrease the prevalence of heart disease, stroke, hypertension, obesity, cancer, and noninsulin-dependent diabetes mellitus by reducing their fat and cholesterol consumption and increasing their fiber intake [13].

Increased dietary awareness has substantially enhanced the relevance of dieticians, nutritionists, and food technologists. There is an increasing demand for functional meat products containing dietary fiber, low levels of fat and cholesterol, reduced contents of sodium chloride and nitrite, a healthy fatty acid profile composition, and added healthenhancing ingredients among consumers worldwide [14]. Nonmeat additives are known to significantly improve the functionality of meat products [15]. Reducing the fat content without noticeably affecting meat product quality and acceptability is challenging [16-18].

Several functional ingredients may be employed to reduce the fat content of goat meat products and thereby improve the nutritional profile $[15,18]$. Nonmeat ingredients from a variety of plants sources are used in functional meat products, such dietary fiber, e.g., psyllium husk [19], drumsticks [20], chia [21], and sugarcane fiber [22], and natural antioxidants, such as the extracts of curry leaves and fenugreek leaves [23], goji berries [24], rosemary [25], and green tea [26]. These functional ingredients are used in processed meat products to enhance the nutritional quality and to retard lipid oxidation via natural antioxidants and are also very effective for the development of low-cost meat products compared to lean meat $[5,10,22,27]$.

Psyllium husk and fenugreek leaves both serve as excellent sources of soluble and insoluble dietary fiber/fractions [28,29]. Psyllium husk is known to have gelling properties with beneficial effects on health, such as improved lipid metabolism [30] and diabetes prevention and control [31], and fenugreek leaves also possess pharmacological properties [32]. The incorporation of fenugreek leaves and psyllium husk can supplement as a source of antioxidants and dietary fiber in goat meat products. The combined use of these two significant dietary fractions could be very useful to enhance the nutritional quality and storage stability of meat products, as well as promote a healthy life. Psyllium husk has bioactive components with cholesterol-lowering properties [33], whereas fenugreek leaves have various functional and medicinal values [34].

To date, no literature reports on the optimal ingredients for functional meat products and their physicochemical properties using a central composite design (CCD). Therefore, this study plans to determine the optimum level of fenugreek leaves and psyllium husk to reduce the fat content in goat meat products and to determine the effect of cholesterol digestibility on optimized meat nuggets in vitro. This work is a novel attempt since no previous studies have reported the optimum combination of these additives (fenugreek leaves and psyllium husk) that may substantially reduce the fat content of goat meat nuggets without significantly affecting other physiochemical properties and digestibility.

Response surface methodology (RSM) is the method of choice since it is a well-known statistical technique to determine the optimum combination of independent variables directed toward minimizing/maximizing an independent variable. RSM may be employed 
to develop, improve, and optimize ingredient levels, processes, or formulations in food technology $[35,36]$. It is a very effective technique to investigate the interaction between a dependent variable and an independent variable and reduces the number of experimental trials needed to complete the experimental design $[37,38]$.

\section{Materials and Methods}

\subsection{Design of Experiment: Formulation of Experimental Functional Meat Nuggets}

Contents of goat meat, fenugreek leaves, and psyllium husk were varied as per the CCD experiments (Table 1) while keeping all other constituents constant. Experiments were set up as per a fully rotatable and orthogonal CCD [32]. Each row of Table 1 corresponds to a single experiment (a total of 24 experiments, eight cube points, six-star points, and ten central points). The rest of the ingredients were kept the same in all 24 experiments (common salt $(2 \%)$, condiment mix and spices mix $(15 \%)$, vegetable oil $(2 \%)$, and soybean flour $(7 \%))$. Boneless goat meat with subcutaneous fats, all spices, psyllium husks, and fresh fenugreek leaves were obtained from a local market.

Table 1. Experimental design: central composite design (CCD), GM: goat meat (g), FL: fenugreek leaves (g), PH: psyllium husk (g), OFC: observed fat content (\%), REPFC: response model-predicted fat content (\%), MC: moisture content (\%), AC: ash content (\%), CF: crude fiber (\%), OA: overall acceptability.

\begin{tabular}{cccccccccc}
\hline GM & FL & PH & OFC & RMPFC & pH & MC & AC & CF & OA \\
\hline 55 & 3 & 1 & 5.85 & 5.83 & 6.59 & 61.8 & 3.88 & 1.09 & 9 \\
55 & 3 & 5 & 5 & 4.97 & 6.71 & 60.2 & 3.90 & 1.78 & 8 \\
55 & 9 & 1 & 5 & 5.07 & 6.51 & 62.1 & 4.02 & 1.21 & 8 \\
55 & 9 & 5 & 4.8 & 4.78 & 6.60 & 61.5 & 4.06 & 1.42 & 7 \\
65 & 3 & 1 & 7 & 7.06 & 6.65 & 63.8 & 3.94 & 1.21 & 8 \\
65 & 3 & 5 & 5.8 & 5.77 & 6.69 & 62.3 & 3.96 & 1.46 & 7 \\
65 & 9 & 1 & 6.2 & 6.27 & 6.49 & 64.1 & 4.17 & 1.81 & 9 \\
65 & 9 & 5 & 5.5 & 5.56 & 6.55 & 63.7 & 4.29 & 1.94 & 7 \\
$51.59 *$ & 6 & 3 & 4.3 & 4.31 & 6.62 & 60.7 & 3.74 & 1.19 & 8 \\
$68.40 * *$ & 6 & 3 & 6.1 & 6.01 & 6.58 & 63.9 & 4.10 & 1.48 & 8 \\
60 & $0.95 *$ & 3 & 6.4 & 6.42 & 6.65 & 62.4 & 3.66 & 1.01 & 8 \\
60 & $11.04 * *$ & 3 & 5.7 & 5.60 & 6.55 & 62.8 & 4.23 & 1.58 & 8 \\
60 & 6 & $0 *$ & 6.6 & 6.48 & 6.47 & 64.3 & 3.65 & 1.07 & 9 \\
60 & 6 & $6.3 * *$ & 5.2 & 5.21 & 6.74 & 60.7 & 3.83 & 1.91 & 7 \\
60 & 6 & 3 & 6 & 5.96 & 6.67 & 63.7 & 3.79 & 1.70 & 8 \\
60 & 6 & 3 & 5.9 & 5.96 & 6.67 & 63.3 & 3.76 & 1.55 & 8 \\
60 & 6 & 3 & 5.8 & 5.96 & 6.68 & 63.8 & 3.78 & 1.59 & 7 \\
60 & 6 & 3 & 6.1 & 5.96 & 6.66 & 63.9 & 3.77 & 1.58 & 8 \\
60 & 6 & 3 & 6.1 & 5.96 & 6.67 & 63.7 & 3.79 & 1.59 & 7 \\
60 & 6 & 3 & 6.1 & 5.96 & 6.68 & 63.5 & 3.78 & 1.58 & 8 \\
60 & 6 & 3 & 5.8 & 5.96 & 6.68 & 63.6 & 3.78 & 1.57 & 7 \\
60 & 6 & 3 & 5.8 & 5.96 & 6.67 & 63.8 & 3.78 & 1.59 & 8 \\
60 & 6 & 3 & 6 & 5.96 & 6.67 & 63.7 & 3.79 & 1.58 & 8 \\
60 & 6 & 3 & 6 & 5.96 & 6.68 & 63.8 & 3.78 & 1.57 & 8 \\
\hline
\end{tabular}

* minimum value; ${ }^{* *}$ maximum value.

\subsection{Quality Parameter Protocols}

Protocols for determining the $\mathrm{pH}$, fat content, moisture content, crude fiber content, ash content, calories, carbohydrate content, and sensory evaluation details are provided in Supplementary Information (SI). The cholesterol content was determined following Gok et al. [39].

\subsection{In Vitro Human Digestion Model}

An in vitro human digestion model was used following the procedure described by Hur, Decker, and McClements [40] and Versantvoort et al. [41] with slight modification. 
Details are provided in Supplementary Information (SI). All inorganic and organic solutions were procured from Sigma (New Delhi, India) at the time of the experiments. Various saliva, gastric, and bile juice compositions were prepared for evaluation of the digestibility of the meat products. An in vitro human digestion model was statistically analyzed by ANOVA using SPSS version 23 software (IBM Corp., Armonk, NY, USA). Duncan's multiple range test was applied to identify significant differences in the means; results are presented as the mean \pm standard deviation. All samples were tested in triplicate.

\subsection{Thiobarbituric Acid-Reacting Substances (TBARS) Lipid Peroxidation Test}

Lipid oxidation of the meat nuggets was evaluated by measuring thiobarbituric acidreactive substances (TBARS); the extraction method used was described by Buege and Aust [42]. The absorbance was determined at $532 \mathrm{~nm}$ using a UV-VIS spectrophotometer (Inkarp Instrument Pvt. Ltd. Hyderabad, India). TBARS were calculated based on a standard curve, and the results are expressed as mg of malondialdehyde (MDA) per kg of meat sample.

\subsection{Response Surface Optimization}

Table 1 shows the experimental formulation of the functional meat nuggets according to the CCD. Minitab was used to determine the quadratic relationship between dependent variables (goat meat, fenugreek leaves, and psyllium husk) and the dependent response variable (fat \%). Multivariable regression analysis was performed to determine the adequacy of the response model given by the following equation:

$$
Y=\beta_{0}+\sum_{i=1}^{3} \beta_{i} x_{i}+\sum_{i=1}^{3} \beta_{i}^{2} x_{i}^{2}+\sum_{i j=1}^{3} \beta_{i j} x_{i} x_{j}
$$

where $Y$ is defined as the response or dependent variable (fat $\%$ ), $\beta_{0}$ is the constant, $\beta_{i}$ is the linear coefficient, $\beta_{i}^{2}$ is the quadratic coefficient, and $\beta_{i j}$ is the interaction coefficient, $x_{i}$ represents the independent variables: i.e., goat meat $\left(x_{1}\right)$, fenugreek leaves $\left(x_{2}\right)$, and psyllium husk $\left(x_{3}\right)$.

\section{Results}

The variation in the fat content (\%) of the goat meat nuggets was obtained from the quadratic response function (Equation (2)) of the content of goat meat and the two functional ingredients, i.e., fenugreek leaves and psyllium husk (Table 1). The quadratic response equation (Equation (2), Table 2) represents the final regressed quadratic equation with real coefficients for the absolute (uncoded) independent variable. The degree of significance of the complete response model and its coefficient are presented in the ANOVA table (Table 2).

The $R^{2}, R^{2}$-adj, and $R^{2}$-pred regression coefficients for the fitness of the response model (Equation (2)) reflect the robust efficiency of the selected quadratic response model (Equation (2), Table 3). The predicted responses from Equation (2) for the variation in the fat content $(\%)$ as a function of goat meat $\left(x_{1}\right)$, fenugreek leaves $\left(x_{2}\right)$, and psyllium husk $\left(x_{3}\right)$ are similar to the experimentally observed values (Figure 1, Table 1). 


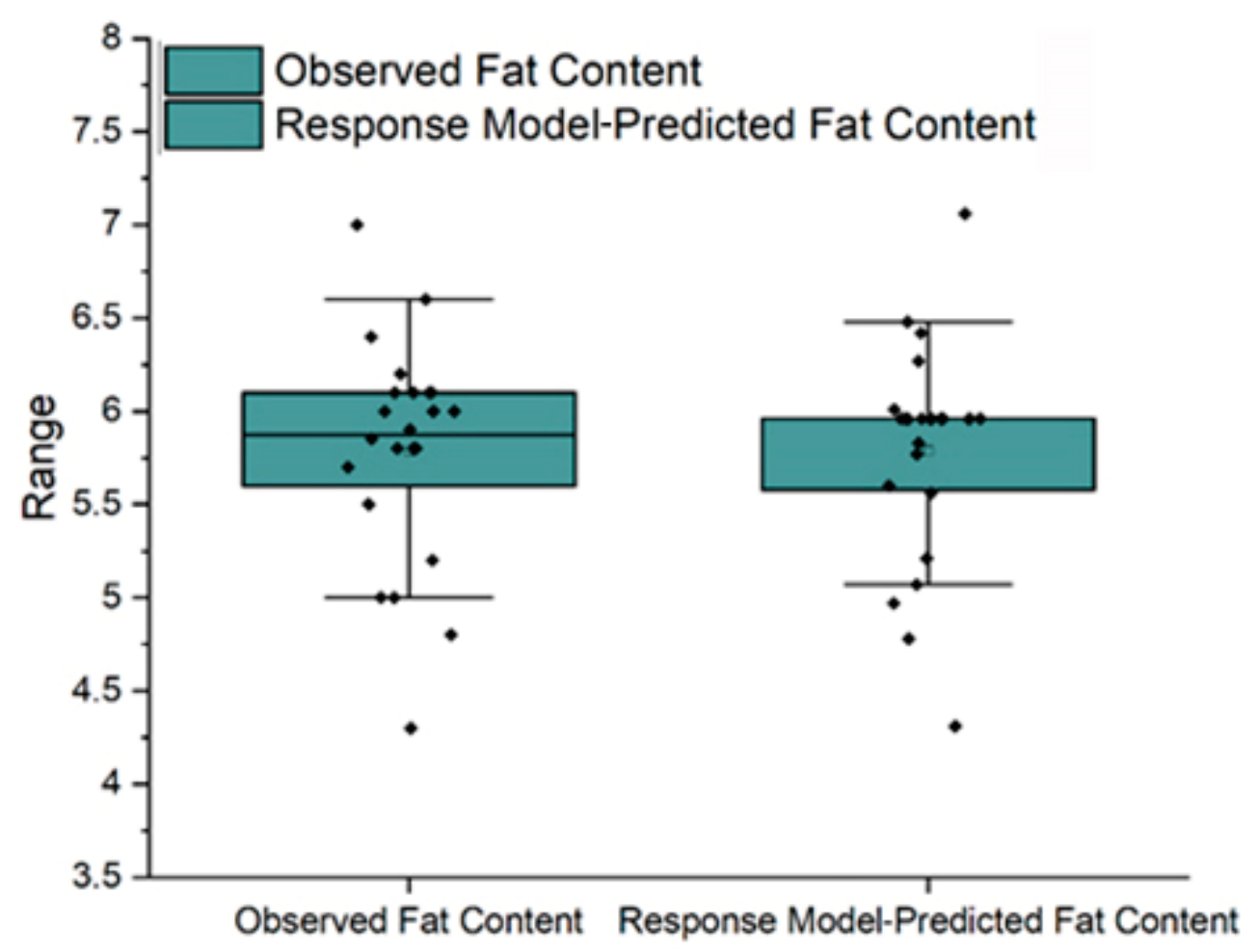

Figure 1. Comparison of observed and response model predictions.

Table 2. ANOVA of the response model.

\begin{tabular}{|c|c|c|c|c|c|}
\hline Term & Coef. & Adj SS & Adj MS & F-Value & $P$-Value \\
\hline Constant $\left(\beta_{0}\right)$ & -41.33 & 7.88454 & 0.87606 & 62.25 & 0.000 \\
\hline Goat meat $(\mathrm{g}) \beta_{1}$ & 1.492 & 3.28529 & 3.28529 & 233.44 & 0.000 \\
\hline Fenugreek leaves (g) $\beta_{2}$ & -0.152 & 0.71591 & 0.71591 & 50.87 & 0.000 \\
\hline Psyllium husk (g) $\beta_{3}$ & 0.341 & 2.06809 & 2.06809 & 146.95 & 0.000 \\
\hline \multicolumn{2}{|c|}{ Overall Linear Coefficient Significance } & 6.06929 & 2.02310 & 143.76 & 0.000 \\
\hline Goat meat $(\mathrm{g})^{*}$ goat meat $(\mathrm{g}) \beta_{1}^{2}$ & -0.01131 & 1.29438 & 1.29438 & 91.98 & 0.000 \\
\hline Fenugreek leaves $(\mathrm{g})^{*}$ fenugreek leaves $(\mathrm{g}) \beta_{2}^{2}$ & 0.00199 & 0.00517 & 0.00517 & 0.37 & 0.554 \\
\hline Psyllium husk $(\mathrm{g})^{*}$ psyllium husk $(\mathrm{g}) \beta_{3}^{2}$ & -0.00740 & 0.01208 & 0.01208 & 0.86 & 0.370 \\
\hline \multicolumn{2}{|c|}{ Overall Quadratic Coefficient Significance } & 1.32036 & 0.44012 & 31.27 & 0.000 \\
\hline Goat meat $(\mathrm{g})^{*}$ fenugreek leaves $(\mathrm{g}) \beta_{12}$ & -0.00042 & 0.00031 & 0.00031 & 0.02 & 0.884 \\
\hline Goat meat (g)* psyllium husk (g) $\beta_{13}$ & -0.01063 & 0.09031 & 0.09031 & 6.42 & 0.024 \\
\hline Fenugreek leaves $(\mathrm{g})^{*}$ psyllium husk $(\mathrm{g}) \beta_{23}$ & 0.02369 & 0.16531 & 0.16531 & 11.75 & 0.004 \\
\hline \multicolumn{2}{|c|}{ Overall, Two-Way Interaction Coefficient Significance } & 0.25594 & 0.08531 & 6.06 & 0.007 \\
\hline
\end{tabular}


Table 3. Optimum response model.

\begin{tabular}{|c|c|c|c|c|c|}
\hline \multicolumn{2}{|c|}{ Quadratic Response Equation (Equation (2)) } & S & $\mathbf{R}^{2}$ & $R^{2}$-(adj) & $R^{2}$-(pred) \\
\hline \multirow{2}{*}{\multicolumn{2}{|c|}{$\begin{array}{l}\text { Fat }(\%)=-41.33+1.492 x_{1}-0.152 x_{2}+0.341 x_{3}- \\
0.01131 x_{1}^{2}+0.00199 x_{2}^{2}-0.00740 x_{3}^{2}- \\
0.00042 x_{1}^{*} x_{2}-0.01063 x_{1}^{*} x_{3}+0.02396 x_{2}^{*} x_{3}\end{array}$}} & 0.118630 & $97.56 \%$ & $95.99 \%$ & $92.99 \%$ \\
\hline & & $\begin{array}{l}\text { Optimum Goat } \\
\text { Meat }(\mathrm{g})\end{array}$ & $\begin{array}{c}\text { Optimum Fenugreek } \\
\text { Leaves }(\mathrm{g})\end{array}$ & \multicolumn{2}{|c|}{$\begin{array}{c}\text { Optimum } \\
\text { Psyllium Husk (g) }\end{array}$} \\
\hline $\begin{array}{l}\text { Minimized fat content }(\%) \\
\text { predicted at optimum values }\end{array}$ & 3.87092 & 51.5910 & 5.23555 & \multicolumn{2}{|c|}{6.36359} \\
\hline $\begin{array}{l}\text { Minimized fat content (\%) } \\
\text { observed at optimum values }\end{array}$ & $3.5 \pm 0.3$ & 51.6 & 5.2 & \multicolumn{2}{|c|}{6.3} \\
\hline Fat content $(\%)$ in control one & $4.9 \pm 2$ & 51.6 & - & \multicolumn{2}{|c|}{-} \\
\hline $\begin{array}{l}\text { Fat content }(\%) \text { in control two } \\
\text { (weight-conserved nuggets) }\end{array}$ & $5.8 \pm 2$ & 63.1 & - & \multicolumn{2}{|c|}{-} \\
\hline
\end{tabular}

The fat content appeared to be significantly affected by all three types of model terms present in the quadratic response model (linear terms: $P$-value: 0.00; quadratic terms: $P$-value: 0.00; two-way interaction terms: $P$-value: 0.00$)$. However, the individual quadratic terms for fenugreek leaves $\beta_{2}^{2}$ and psyllium husk $\beta_{3}^{2}$ and two-way interaction terms for goat meat $(\mathrm{g})^{*}$ fenugreek leaves $(\mathrm{g}) \beta_{12}$ were statistically insignificant. The Pareto chart (Figure 2) illustrates the significance of the individual response model terms (linear terms: $\mathrm{A}, \mathrm{B}$, and $\mathrm{C}$; quadratic terms: $\mathrm{AA}, \mathrm{BB}$, and $\mathrm{CC}$; two-way interaction terms: $\mathrm{AB}, \mathrm{AC}$, and $\mathrm{BC}$ ) in a hierarchy, with the top-most value having the most significant effect on the fat content of the meat nuggets, and vice versa. The linear terms for goat meat and psyllium husk and goat meat's quadratic effect appeared to have the most significant fat content effect, closely followed by the linear effect of fenugreek leaves and the two-way interaction effect of fenugreek leaves and psyllium husk. The two-way interaction effect of goat meat and psyllium husk, although significant, approached the standardized cut-off limit (2.14) for $95 \%$ significance $(\alpha=0.05 \%)$. Below this limit, none of the model terms significantly affected the fat content of the nuggets. The two remaining quadratic terms (for psyllium husk and fenugreek leaves) and two-way interaction terms for goat meat and fenugreek leaves showed no significant effect on the fat content of the nuggets.

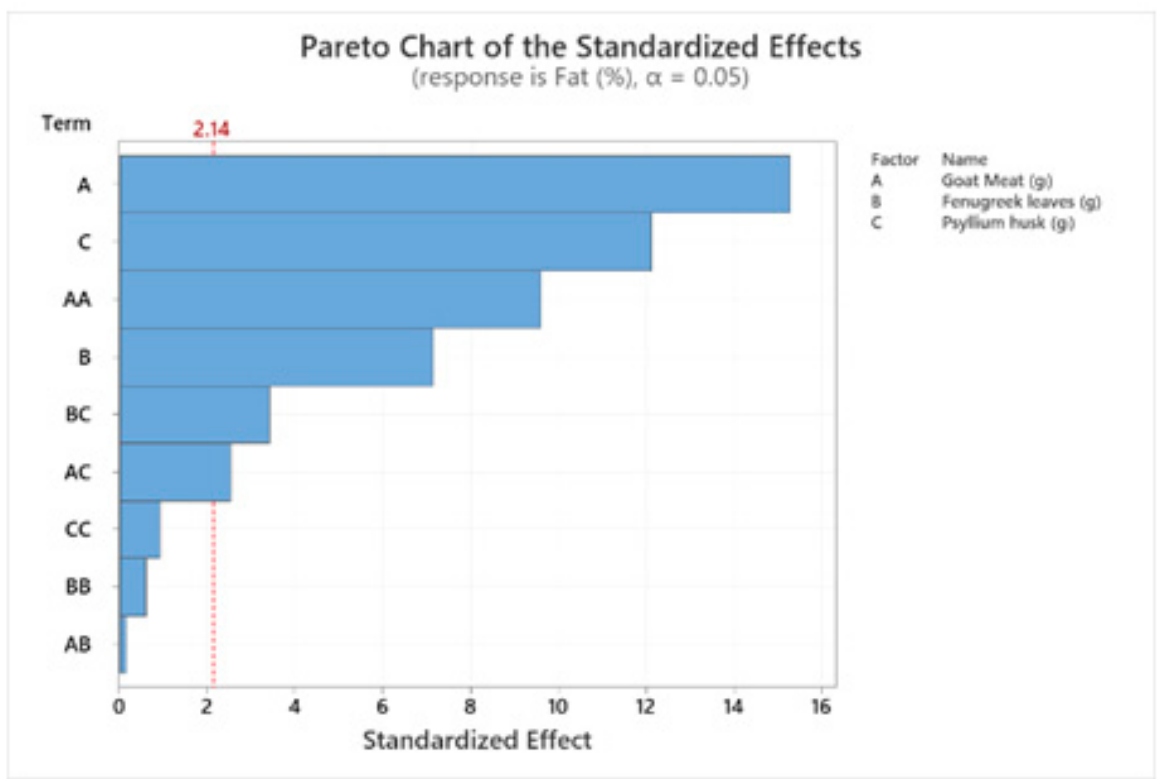

Figure 2. Pareto chart of standardized effects (linear terms: $A, B$, and C; quadratic terms: AA, BB, and $\mathrm{CC}$; two-way interaction terms: $\mathrm{AB}, \mathrm{AC}$, and $\mathrm{BC})$. 
The main effect of independent variables on the fat content of the nuggets is visible in Figure 3. The fat content increased proportionally with the increase in goat meat content. Increases in the contents of fenugreek leaves ( 3 to $9 \mathrm{~g}$ ) and psyllium husk ( 1 to $5 \mathrm{~g}$ ) appeared to have a negative effect on the fat content, with values of $6.4 \%$ to $5.5 \%$ and $6.5 \%$ to $5.2 \%$, respectively.

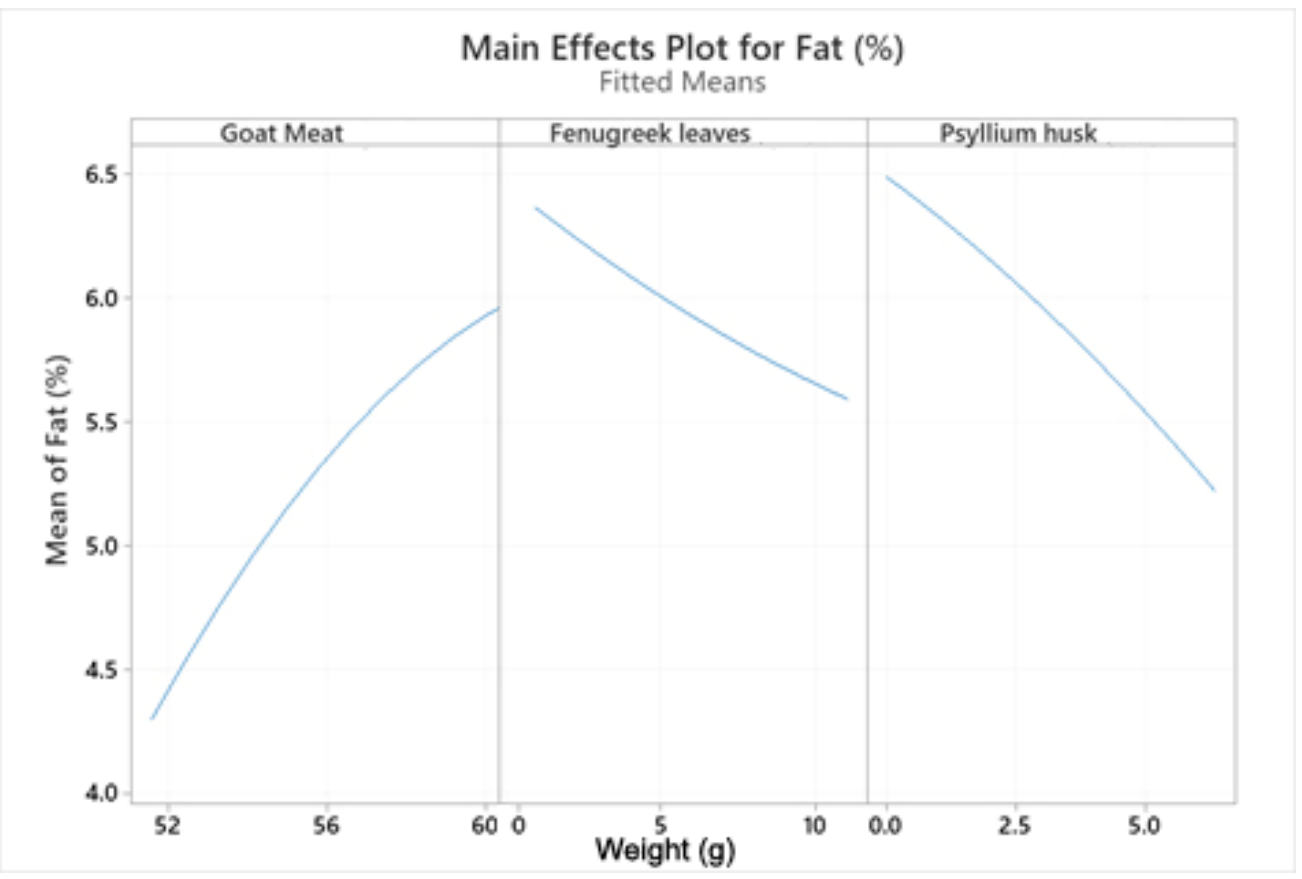

Figure 3. Individual main effects plot for fat (\%).

Contour plots and response surfaces were generated to visualize the effect of any two variables (keeping the third one at central values/hold values) on the fat content of the nuggets (Figure 4a-f). The hold values for goat meat, fenugreek leaves, and psyllium husk were $60 \mathrm{~g}, 6 \mathrm{~g}$, and $3.18 \mathrm{~g}$, respectively. The contour in Figure 4 a highlights the area of the lowest fat content $(<4.5 \%)$ in a region corresponding to the lowest goat meat and highest fenugreek leaf contents $(\sim>4.5 \mathrm{~g})$. An increase in the goat meat requires additional fenugreek leaves to maintain the fat content below $4.5 \%$. A similar trend was observed for the combined effect of psyllium husk and goat meat on the fat content (Figure 4b). A higher goat meat content requires a proportional increase in psyllium husk to maintain a minimal fat content $(<4.5 \%)$. However, a prominent difference between the two contours (Figure $4 a, b)$ lies in the content of functional ingredients required to keep identical low levels of fat (\%) in the nuggets. Noticeably lower levels of psyllium husk were required to reduce the fat content to less than $4.5 \%$ compared to fenugreek leaves. The lowest fat content was observed in the area corresponding to the maximum functional additive regions (Figure 4c). Response surfaces (Figure 4d-f) also reflected a similar trend. A higher goat meat content requires even more functional additives (to maintain the lower fat \%) than those considered in this study. More than $6 \mathrm{~g}$ of psyllium husk and/or more than $10 \mathrm{~g}$ of fenugreek leaves would be required to maintain the fat content at less than $4.5 \%$ in the case of enhancing the nugget meat content. Psyllium husk appears to be more effective in upholding lower levels of fat compared to similar levels of added fenugreek leaves. This is evident from the slightly depressed outer edge of the response surface defined by the variation in the psyllium husk and goat meat (Figure 4e). The central diagonal region corresponding to the upper quartile levels of fenugreek leaves and psyllium husk appeared to produce analogous lower levels of fat when compared to the observed fat levels near the individual maximal extremities of the functional additives (Figure 4f). This suggests 
that the combination of fenugreek leaves and psyllium becomes effective only above the respective median values considered in this study.
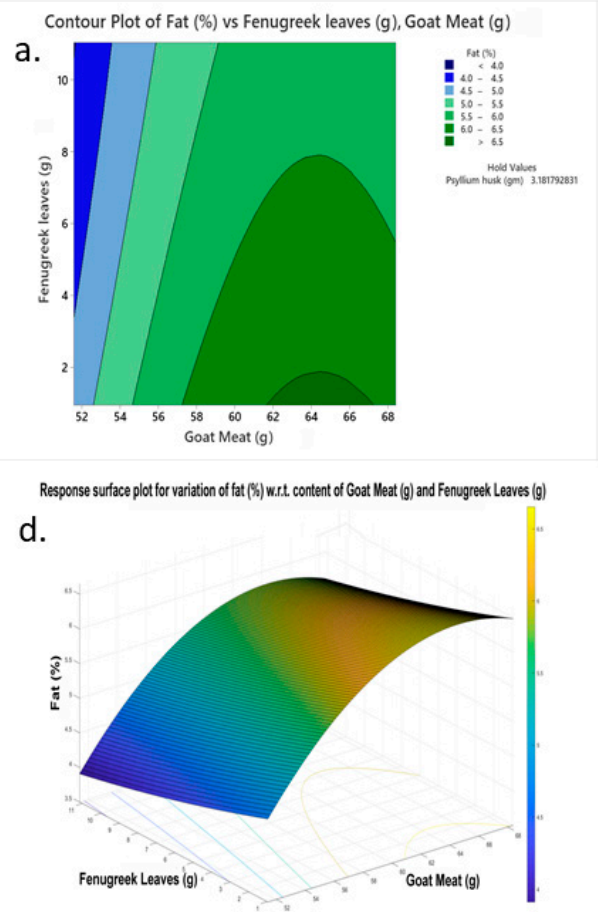

d.
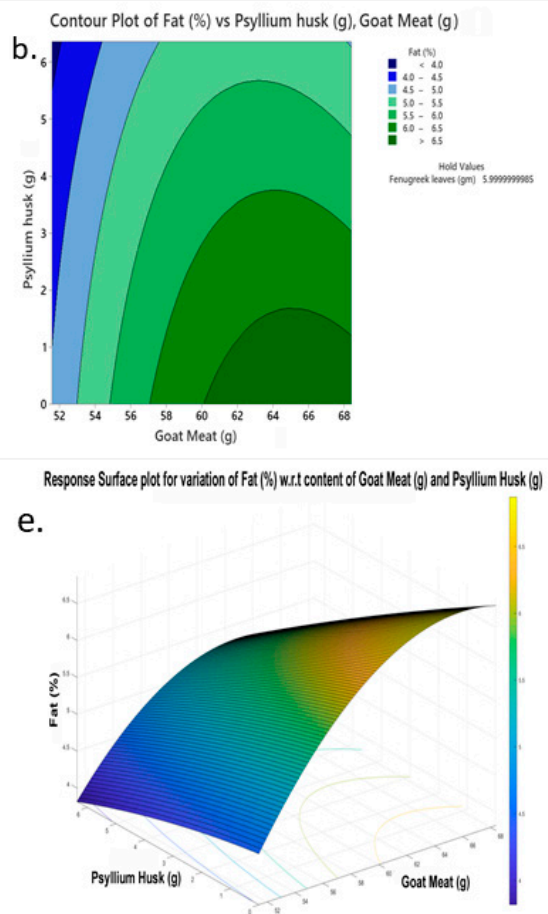
e.

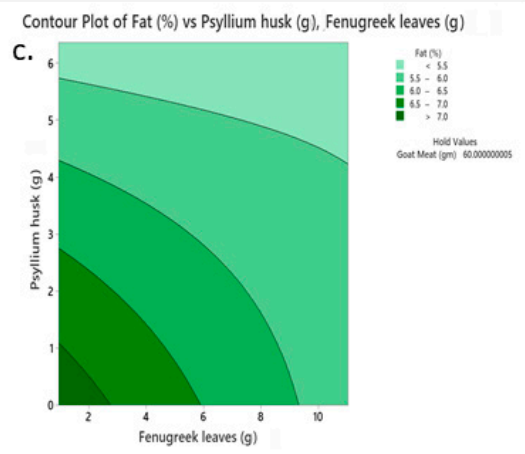

Response Surface Plot for varaidion of fat (y) w..t. content of Goat Meat (g) and Pyyllium Husk (g) f.

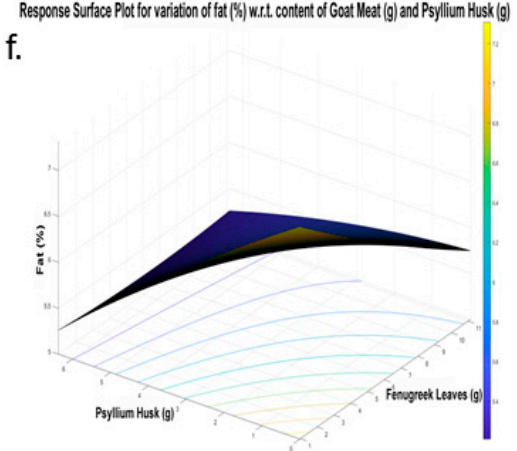

Figure 4. Contour and response surface plots. (a): Contour plot of fat (\%) vs. FL (g) and GM (g); (b): contour plot of fat (\%) vs. PH (g) and GM (g); (c): contour plot of fat (\%) vs. PH (g) and FL (g); (d): response surface plot shows the effect of the fat content with FL and GM (g); (e): response surface plot shows the effect of the fat content with PH and goat meat (g); (f): response surface plot shows the interactive effect of the fat content with FL and PH.

The quadratic response equation (Equation (2)) was optimized using the response optimizer module of Minitab (for details, refer to the response optimizer section in Supplementary Information). The optimum solution and minimal fat content predicted and observed at optimum values are presented in Table 3 . The observed minimized fat content was determined in triplicate at the optimum combination of goat meat, fenugreek leaves, and psyllium husk. The remaining parameters were kept the same as in the control nuggets. The fat content of the nuggets with the optimized functional additives decreased by $\sim 26.5 \%$ compared to the control nuggets with the same content of goat meat (control one).

The fat content was also compared with the weight-conserved nuggets (control two), wherein the masses of psyllium husk and fenugreek leaves were replaced with goat meat $(51.6+5.2+6.3=63.1 \mathrm{~g})$ to conserve the net weight of the nuggets. An overall fat content decrease of $\sim 39 \%$ was observed. This significant reduction in the fat content was attributed to the optimum levels of functional additives (fenugreek leaves and psyllium husk). Table S4 presents the final compositions of the optimized and control (one and two) functional nuggets.

\section{Discussion}

The fat content is considered an important parameter contributing to the texture, flavor, mouthfeel, and overall perception of meat [43]. Reducing the fat content with suitable replacements without affecting the properties of a product is a challenging task [16]. In the present study, the fat content of goat meat nuggets was successfully maintained below $4 \%$ with an optimized combination of functional additives (fenugreek leaves and psyllium husk). The synergistic relationship of these two functional additives proved 
to be an effective criterion for their application as fat content attenuators in goat meat formulations. The incorporation of functional additives as sources of dietary fiber (DF) and antioxidant fractions in meat products improves product image and fulfills customer demand. DF and antioxidants are important dietary fractions that promote human health. The incorporation of DF, as well as antioxidant fractions, could enhance the nutritional quality and storage stability of meat products, thereby promoting a healthy lifestyle [44]. Mehta and associates [45] added 2\% psyllium husk to their chicken product, decreasing the fat content. In addition, Zargar et al. [46] and Jairath et al. [47] added pumpkin seed to chicken sausage and corn starch to buffalo calf meat sausages as fat replacers, which helped reduce the fat content of the developed products. Furthermore, Rokib and coworkers [48] formulated low-fat chicken sausages with the addition of rice and wheat flour.

The effects of the levels of functional additives (fenugreek leaves and psyllium husk) and the goat meat content on the moisture content (MC), ash content (AC), crude fiber $(\mathrm{CF})$, and overall acceptability (OA) are listed in Table 1. Optimized nuggets were formulated according to Table S4, and their nutritional properties were evaluated and compared with controls one and two (Table S2). The variations in MC, AC, CF, and OA as a function of functional additives and the goat meat content are illustrated in contour plots (Figures S1 and S4). Higher moisture contents were observed with increasing FL and goat meat (Figure S1a,c). PH appeared to have minimal contribution toward MC, with increasing $\mathrm{PH}$ decreasing the moisture of the final product (Figure S1b). This is in agreement with an earlier report of moisture content variation with the addition of psyllium husk in chicken meat rolls [19], whereas lotus (Nelumbo nucifera) rhizome, a known DF and antioxidant source, was observed to increase the moisture and ash content in cooked sausage [49].

In our findings (Figure S2a-c), the ash content increased with increasing goat meat and fenugreek leaf contents; however, an increase in psyllium husk did not significantly affect the ash content. Madane and associates noticed an improvement in the ash content of chicken nuggets with drumstick (Moringa oleifera) flower as a source of antioxidants and dietary fiber [20]. The addition of psyllium husk and fenugreek leaves significantly improved the fiber content of the goat meat nuggets (Figure S3a-c). Goat meat has high biological protein, mineral, and vitamin contents, but almost no fiber; therefore, incorporating fiber and antioxidant fractions into goat meat products is nutritionally beneficial. The fiber content of the meat products increased with increasing PH and FL ratios. The addition of antioxidant and fiber contents to meat products improves their nutritional quality compared to traditional meat products [10]. The effect of goat meat with psyllium husk and fenugreek leaves on the OA of the meat products is shown in Figure S4a-c. The higher percentage of goat meat values demonstrated higher acceptability of meat products, with the incorporation of fenugreek leaves and psyllium husk showing a slightly negative effect on acceptability. A similar trend was indicated by previous research during the incorporation of antioxidants and dietary fiber [10]. The functional additives and ingredients obtained from natural sources proved to be of great nutritional value [50]. These functional additives influence the physicochemical properties of meat products and enrich their nutritional and functional values.

The synergistic effect of phytochemicals, improving bioavailability of nutrients and gastrointestinal function and facilitating mechanisms of nutrient absorption, results in better control and management of systemic issues, such as diabetes mellitus and cardiovascular disease [51-56]. Various human and animal studies revealed the mechanism of fenugreek leaves and psyllium husk in the mediation of fat reduction $[57,58]$. These studies discussed the bioavailability/bio-accessibility of the nutrients related to the chemical and physical interactions between phenolic and dietary fiber fractions in the digestive tract [58]. Researchers reported the positive relationship between DF and the phenolic fraction and intestinal health due to the scavenging of free radicals and the effects of DF pro-oxidants [52], thereby constructing a healthy antioxidant atmosphere in the lumen [59]. Due to the partial fermentation of DF and phenolic compounds, non-absorbable and non-fermentable forms of DF reach the large intestine [60]. Short-chain fatty acids (SCFA), released during partial 
fermentation, act synergistically with phenolics (antioxidants) and modulate the expression of genes associated with several CVDs [61]. DF also significantly affects the bioavailability, microbial composition, and gastrointestinal digestion of nutrients. DF is also known to alter the mechanism of absorption in humans and animals [62]. Insoluble dietary fiber (IDF) is related to the regulation of the intestinal tract, although soluble fiber (SDF) is linked to the reduction in cholesterol levels and the absorption of intestinal glucose [30]. Decreased cholesterol reabsorption was observed in the in vitro human digestive model (Table S2). The soluble fiber fraction binds with the bile acids in the small intestine, forming a complex that prevents bile reabsorption from the small intestine. This improves the production and secretion of bile acids to replace lost acids [63]. Subsequently, fat and cholesterol are withdrawn from the circulation to produce bile acids, thus lowering blood cholesterol levels [64]. Bile acids, which are synthesized in the liver from cholesterol, are secreted into the intestine (small), which is the main cholesterol metabolism pathway. Bile acids are reabsorbed in the ileum and recycled to the liver for further secretion into the small intestine by enterohepatic circulation, subsequently reducing the ratio of bile acid synthesis [65].

\section{Conclusions}

Optimal functional additives may substantially enhance a processed food product's nutritional value without any significant effect on its $\mathrm{OA}$ and taste/texture/shelf-life. A simulated in vitro human digestive model suggested better cholesterol management for the final product with optimal functional ingredients. The fat-attenuated composition of goat meat nuggets with optimum functional additives (FL and $\mathrm{PH}$ ) was prescribed and successfully validated. The composition is available for further enhancement and modifications as per specific requirements.

Supplementary Materials: The following are available online at https://www.mdpi.com/2227-971 7/9/3/475/s1, Figures S1-S4: Contour plots, Table S1: The concentration of various synthetic juices, Table S2: Comparison of nutritional quality of functionally optimized products with control; Table S3: Response optimizer module; Table S4: Composition of optimized and control nuggets.

Author Contributions: Conceptualization and design T.K., Z.R.A.A.A. and S.K.; investigation, T.K., Z.R.A.A.A. and M.A.K.; data analysis M.A.K., Z.R.A.A.A., S.K. and S.H.; original draft-writing T.K., M.A.K., S.K. and Z.R.A.A.A.; writing-review and editing, M.A.K., Z.R.A.A.A., S.K. and S.H.; visualization, M.A.K., Z.R.A.A.A., S.K. and S.H.; supervision, Z.R.A.A.A., S.K. and S.H. All authors have read and agreed to the published version of the manuscript.

Funding: UGC (University Grants Commission, India) Junior Research Fellowship (UGC-JRF) supported this research.

Institutional Review Board Statement: Not applicable.

Informed Consent Statement: Not applicable.

Data Availability Statement: Data is contained within the article and supplementary material.

Acknowledgments: The author Tahreem Kausar sincerely acknowledges the Head of Department, Department of Food Technology, SIST (School of Interdisciplinary Sciences and Technology), Jamia Hamdard, New Delhi, India, for providing lab space to conduct this research.

Conflicts of Interest: The authors declare no conflict of interest.

\section{References}

1. De Smet, S.; Vossen, E. Meat: The balance between nutrition and health. A review. Meat Sci. 2016, 120, 145-156. [CrossRef]

2. Mazhangara, I.R.; Chivandi, E.; Mupangwa, J.F.; Muchenje, V. The potential of goat meat in the red meat industry. Sustainability 2019, 11, 3671. [CrossRef]

3. Ribeiro, R.D.X.; Medeiros, A.N.; Oliveira, R.L.; de Araújo, G.G.L.; Queiroga, R.d.C.d.E.; Ribeiro, M.D.; Silva, T.M.; Bezerra, L.R.; Oliveira, R.L. Palm kernel cake from the biodiesel industry in goat kid diets. Part 2: Physicochemical composition, fatty acid profile and sensory attributes of meat. Small Rumin. Res. 2018, 165, 1-7. [CrossRef] 
4. Gopalan, C.; Ramasastri, B.V.; Balasubramanian, S.C. Foods and their nutrient content. In Nutritive Value of Indian Foods; National Institute of Nutrition, ICMR: Hyderabad, India, 2004; pp. 27-29.

5. Madruga, M.S.; Medeiros, E.J.L.d.; Sousa, W.H.d.; Cunha, M.d.G.G.; Pereira Filho, J.M.; Queiroga, R.d.C.R.d.E. Chemical composition and fat profile of meat from crossbred goats reared under feedlot systems. Rev. Bras. de Zootec. 2009, 38, 547-552. [CrossRef]

6. Al-Shaar, L.; Satija, A.; Wang, D.D.; Rimm, E.B.; Smith-Warner, S.A.; Stampfer, M.J.; Hu, F.B.; Willett, W.C. Red meat intake and risk of coronary heart disease among US men: Prospective cohort study. BMJ 2020, 371. [CrossRef]

7. Larsson, S.C.; Wolk, A. Meat consumption and risk of colorectal cancer: A meta-analysis of prospective studies. Int. J. Cancer 2006, 119, 2657-2664. [CrossRef] [PubMed]

8. Biesalski, H.K. Meat as a component of a healthy diet-are there any risks or benefits if meat is avoided in the diet? Meat Sci. 2005, 70, 509-524. [CrossRef]

9. Dhingra, D.; Michael, M.; Rajput, H.; Patil, R.T. Dietary fiber in foods: A review. J. Food Sci. Technol. 2012, 49, 255-266. [CrossRef] [PubMed]

10. Das, A.K.; Nanda, P.K.; Madane, P.; Biswas, S.; Das, A.; Zhang, W.; Lorenzo, J.M. A comprehensive review on antioxidant dietary fiber enriched meat-based functional foods. Trends Food Sci. Technol. 2020, 99, 323-336. [CrossRef]

11. Chao, A.; Thun, M.J.; Connell, C.J.; McCullough, M.L.; Jacobs, E.J.; Flanders, W.D.; Rodriguez, C.; Sinha, R.; Calle, E.E. Meat consumption and risk of colorectal cancer. JAMA 2005, 293, 172-182. [CrossRef]

12. Hogg, N. Red meat and colon cancer: Heme proteins and nitrite in the gut. A commentary on "diet-induced endogenous formation of nitroso compounds in the GI tract". Free Radic. Biol. Med. 2007, 43, 1037. [CrossRef] [PubMed]

13. Block, G.; Gillespie, C.; Rosenbaum, E.H.; Jenson, C. A rapid food screener to assess fat and fruit and vegetable intake. Am. J. Prev. Med. 2000, 18, 284-288. [CrossRef]

14. Kausar, T.; Kausar, M.A.; Azad, Z. Improving the quality and shelf life of goat meat patties with herb and husk incorporation. Biochem. Cell. Arch. 2018, 18, 1569-1576.

15. Kausar, T.; Hanan, E.; Ayob, O.; Praween, B.; Azad, Z. A review on functional ingredients in red meat products. Bioinformation 2019, 15, 358. [CrossRef]

16. Robel, C.; Ktenioudaki, A.; Gallagher, E. Inulin and oligofructose as fat and sugar substitutes in quick breads (scones): A mixture design approach. Eur. Food Res. Technol. 2011, 233, 167.

17. Nardoia, M.; Ruiz-Capillas, C.; Herrero, A.M.; Pintado, T.; Jimnez-Colmenero, F.; Chamorro, S.; Brenes, A. Effect of added grape seed and skin on chicken thigh patties during chilled storage. Int. J. Food Nutr. Sci. 2017, 4, 67-73.

18. Das, A.K.; Rajkumar, V.; Verma, A.K. Bael pulp residue as a new source of antioxidant dietary fiber in goat meat nuggets. J. Food Process. Preserv. 2015, 39, 1626-1635. [CrossRef]

19. Mehta, N.; Ahlawat, S.S.; Sharma, D.P.; Dabur, R.S.; Yadav, S. Optimization and quality evaluation of dietary fiber rich chicken meat rolls incorporated with psyllium husk. Fleischwirtsch. Int. 2016, 3, 65-70.

20. Madane, P.; Das, A.K.; Pateiro, M.; Nanda, P.K.; Bandyopadhyay, S.; Jagtap, P.; Barba, F.J.; Shewalkar, A.; Maity, B.; Lorenzo, J.M. Drumstick (Moringa oleifera) flower as an antioxidant dietary fiber in chicken meat nuggets. Foods 2019, 8, 307. [CrossRef] [PubMed]

21. Pintado, T.; Herrero, A.M.; Jiménez-Colmenero, F.; Ruiz-Capillas, C. Strategies for incorporation of chia (Salvia hispanica L.) in frankfurters as a health-promoting ingredient. Meat Sci. 2016, 114, 75-84. [CrossRef]

22. Fang, Z.; Lin, P.; Ha, M.; Warner, R.D. Effects of incorporation of sugarcane fiber on the physicochemical and sensory properties of chicken sausage. Int. J. Food Sci. Technol. 2019, 54, 1036-1044. [CrossRef]

23. Devatkal, S.K.; Thorat, P.R.; Manjunatha, M.; Anurag, R.K. Comparative antioxidant effect of aqueous extracts of curry leaves, fenugreek leaves and butylated hydroxytoluene in raw chicken patties. J. Food Sci. Technol. 2012, 49, 781-785. [CrossRef] [PubMed]

24. Mitev, A.; Kuzelov, A.; Josevska, E. Influence of Goji berries on oxidative changes, microbiological status and chemical properties of sausages. Agric. Sci. Technol. 2018, 10, 70-73. [CrossRef]

25. Pereira, D.; Pinheiro, R.S.; Heldt, L.F.S.; Moura, C.d.; Bianchin, M.; Almeida, J.d.F.; Reis, A.l.S.d.; Ribeiro, I.S.; Haminiuk, C.W.I.; Carpes, S.T. Rosemary as natural antioxidant to prevent oxidation in chicken burgers. Food Sci. Technol. 2017, 37, 17-23. [CrossRef]

26. Lorenzo, J.M.; Munekata, P.E.S. Phenolic compounds of green tea: Health benefits and technological application in food. Asian Pac. J. Trop. Biomed. 2016, 6, 709-719. [CrossRef]

27. Bhat, Z.F.; Bhat, H. Functional meat products: A review. Int. J. Meat Sci. 2011, 1, 1-14. [CrossRef]

28. Verma, A.; Mogra, R. Psyllium (Plantago ovata) husk: A wonder food for good health. Int. J. Sci. Res. 2013, 4, $1581-1585$.

29. Punna, R.; Rao Paruchuri, U. Effect of maturity and processing on total, insoluble and soluble dietary fiber contents of Indian green leafy vegetables. Int. J. Food Sci. Nutr. 2004, 55, 561-567. [CrossRef]

30. Rodriguez, R.; Jimenez, A.; Fernandez-Bolanos, J.; Guillen, R.; Heredia, A. Dietary fiber from vegetable products as source of functional ingredients. Trends Food Sci. Technol. 2006, 17, 3-15. [CrossRef]

31. Kendall, C.W.C. The health benefits of Psyllium. Can. J. Diet. Pract. Res. 2004, 65, A1.

32. Sumayya, A.R.; Sivagami, S.; Nabeelah, A. Screening and biochemical quantification of phytochemicals in fenugreek (Trigonella foenum-graecum). Res. J. Pharm. Biol. Chem. Sci. 2012, 3, 165-169. 
33. Franco, E.A.N.; Sanches-Silva, A.; Ribeiro-Santos, R.; de Melo, N.R. Psyllium (Plantago ovata Forsk): From evidence of health benefits to its food application. Trends Food Sci. Technol. 2020, 96, 166-175. [CrossRef]

34. Hanafy, R.S.; Akladious, S.A. Physiological and molecular studies on the effect of gamma radiation in fenugreek (Trigonella foenum-graecum L.) plants. J. Genet. Eng. Biotechnol. 2018, 16, 683-692. [CrossRef] [PubMed]

35. Ahmad, M.N.; Mat Noh, N.A.; Abdullah, E.N.; Yarmo, M.A.; Mat Piah, M.B.; Ku Bulat, K.H. Optimization of a protease extraction using a statistical approach for the production of an alternative meat tenderizer from Spondias cytherea roots. J. Food Process. Preserv. 2019, 43, e14192. [CrossRef]

36. Louaer, M.; Zermane, A.; Larkeche, O.; Meniai, A.H. Experimental study and optimization of the extraction of Algerian date stones oil (Phoenix dactylifera L.) using supercritical carbon dioxide. J. Food Process Eng. 2020, 42, e13049. [CrossRef]

37. Singh, J.S.; Koushal, S.; Kumar, A.; Vimal, S.R.; Gupta, V.K. Book review: Microbial inoculants in sustainable agricultural productivity-Vol. II: Functional application. Front. Microbiol. 2017, 7, 2105. [CrossRef]

38. Ahmad, M.N.; Liew, S.L.; Yarmo, M.A.; Said, M. Optimization of protease extraction from horse mango (Mangifera foetida Lour) kernels by a response surface methodology. Biosci. Biotechnol. Biochem. 2012, 76, 1438-1444. [CrossRef] [PubMed]

39. Gok, V.; Akkaya, L.; Obuz, E.; Bulut, S. Effect of ground poppy seed as a fat replacer on meat burgers. Meat Sci. 2011, 89, 400-404. [CrossRef] [PubMed]

40. Hur, S.J.; Lee, S.Y.; Moon, S.S.; Lee, S.J. In vitro effects of cooking methods on digestibility of lipids and formation of cholesterol oxidation products in pork. Korean J. Food Sci. Anim. Resour. 2014, 34, 280. [CrossRef]

41. Versantvoort, C.H.M.; Oomen, A.G.; Van de Kamp, E.; Rompelberg, C.J.M.; Sips, A.n.J.A.M. Applicability of an in vitro digestion model in assessing the bioaccessibility of mycotoxins from food. Food Chem. Toxicol. 2005, 43, 31-40. [CrossRef] [PubMed]

42. Buege, J.A.; Aust, S.D. [30] Microsomal lipid peroxidation. In Methods in Enzymology; Elsevier: Amsterdam, The Netherlands, 1978; Volume 52, pp. 302-310.

43. Zoulias, E.I.; Oreopoulou, V.; Tzia, C. Textural properties of low-fat cookies containing carbohydrate-or protein-based fat replacers. J. Food Eng. 2002, 55, 337-342. [CrossRef]

44. Madane, P.; Das, A.K.; Nanda, P.K.; Bandyopadhyay, S.; Jagtap, P.; Shewalkar, A.; Maity, B. Dragon fruit (Hylocereus undatus) peel as antioxidant dietary fiber on quality and lipid oxidation of chicken nuggets. J. Food Sci. Technol. 2019, 57, 1449-1461. [CrossRef] [PubMed]

45. Mehta, N.; Ahlawat, S.S.; Sharma, D.P.; Yadav, S.; Arora, D. Development and quality evaluation of chicken patties incorporated with psyllium husk. Haryana Vet. 2013, 52, 6-11.

46. Zargar, F.A.; Kumar, S.; Bhat, Z.F.; Kumar, P. Effect of pumpkin on the quality characteristics and storage quality of aerobically packaged chicken sausages. SpringerPlus 2014, 3, 39. [CrossRef]

47. Jairath, G.; Sharma, D.P.; Dabur, R.S.; Singh, P.K.; Bishnoi, S. Standardization of corn starch as a fat replacer in buffalo calf meat sausages and its effect on the quality attributes. Indian J. Anim. Res. 2018, 52, 1521-1525. [CrossRef]

48. Rokib, M.; Habib, M.; Hashem, M.A.; Ali, M.S. Value addition of low fat chicken sausage with rice and wheat flour. Bangladesh J. Anim. Sci. 2019, 48, 99-107. [CrossRef]

49. Ham, Y.-K.; Hwang, K.-E.; Song, D.-H.; Kim, Y.-J.; Shin, D.-J.; Kim, K.-I.; Lee, H.-J.; Kim, N.-R.; Kim, C.-J. Lotus (Nelumbo nucifera) rhizome as an antioxidant dietary fiber in cooked sausage: Effects on physicochemical and sensory characteristics. Korean J. Food Sci. Anim. Resour. 2017, 37, 219. [CrossRef]

50. Fasseas, M.K.; Mountzouris, K.C.; Tarantilis, P.A.; Polissiou, M.; Zervas, G. Antioxidant activity in meat treated with oregano and sage essential oils. Food Chem. 2008, 106, 1188-1194. [CrossRef]

51. Lairon, D.; Arnault, N.; Bertrais, S.; Planells, R.; Clero, E.; Hercberg, S.; Boutron-Ruault, M.-C. Dietary fiber intake and risk factors for cardiovascular disease in French adults. Am. J. Clin. Nutr. 2005, 82, 1185-1194. [CrossRef] [PubMed]

52. Schaafsma, G. Health claims, options for dietary fiber. Diet. Fiber Bioact. Carbohydr. Food Feed 2004, 27-38.

53. Weickert, M.O.; Pfeiffer, A.F.H. Metabolic effects of dietary fiber consumption and prevention of diabetes. J. Nutr. 2008, 138, 439-442. [CrossRef] [PubMed]

54. Donovan, J.L.; Manach, C.; Faulks, R.M.; Kroon, P.A. Absorption and metabolism of dietary plant secondary metabolites. In Plant Secondary Metabolites: Occurrence, Structure and Role in the Human Diet; Wiley-Blackwell: Oxford, UK, 2006 ; pp. $303-351$.

55. Muraki, I.; Imamura, F.; Manson, J.E.; Hu, F.B.; Willett, W.C.; van Dam, R.M.; Sun, Q. Fruit consumption and risk of type 2 diabetes: Results from three prospective longitudinal cohort studies. BMJ 2013, 347, f5001. [CrossRef] [PubMed]

56. Yadav, U.C.S.; Baquer, N.Z. Pharmacological effects of Trigonella foenum-graecum L. in health and disease. Pharm. Biol. 2014, 52, 243-254. [CrossRef] [PubMed]

57. Roberts, K.T. The potential of fenugreek (Trigonella foenum-graecum) as a functional food and nutraceutical and its effects on glycemia and lipidemia. J. Med. Food 2011, 14, 1485-1489. [CrossRef] [PubMed]

58. Quirós-Sauceda, A.E.; Palafox-Carlos, H.; Sáyago-Ayerdi, S.G.; Ayala-Zavala, J.F.; Bello-Perez, L.A.; Alvarez-Parrilla, E.; De La Rosa, L.A.; González-Córdova, A.F.; González-Aguilar, G.A. Dietary fiber and phenolic compounds as functional ingredients: Interaction and possible effect after ingestion. Food Funct. 2014, 5, 1063-1072. [CrossRef]

59. Perez-Jimenez, J.; Serrano, J.; Tabernero, M.; Arranz, S.; Diaz-Rubio, M.E.; Garcia-Diz, L.; Goni, I.; Saura-Calixto, F. Bioavailability of phenolic antioxidants associated with dietary fiber: Plasma antioxidant capacity after acute and long-term intake in humans. Plant Foods Hum. Nutr. 2009, 64, 102-107. [CrossRef] 
60. Metzler, B.U.; Mosenthin, R. A review of interactions between dietary fiber and the gastrointestinal microbiota and their consequences on intestinal phosphorus metabolism in growing pigs. Asian-Australas. J. Anim. Sci. 2008, 21, 603-615. [CrossRef]

61. Tang, Y.; Chen, Y.; Jiang, H.; Nie, D. The role of short-chain fatty acids in orchestrating two types of programmed cell death in colon cancer. Autophagy 2011, 7, 235-237. [CrossRef]

62. Adams, S.; Sello, C.T.; Qin, G.-X.; Che, D.; Han, R. Does dietary fiber affect the levels of nutritional components after feed formulation? Fibers 2018, 6, 29. [CrossRef]

63. Terpstra, A.H.M.; Lapre, J.A.; De Vries, H.T.; Beynen, A.C. Hypocholesterolemic effect of dietary psyllium in female rats. Ann. Nutr. Metab. 2000, 44, 223-228. [CrossRef]

64. Rodriguez-Cabezas, M.E.; Galvez, J.; Camuesco, D.; Lorente, M.D.; Concha, A.; Martinez-Augustin, O.; Redondo, L.; Zarzuelo, A. Intestinal anti-inflammatory activity of dietary fiber (Plantago ovata seeds) in HLA-B27 transgenic rats. Clin. Nutr. 2003, 22, 463-471. [CrossRef]

65. Rakita, S.; Spasevski, N.; Čolović, D.; Popović, S.; Ikonić, P.; Čolović, R.; Lević, J. The influence of laying hens' diet enriched with omega-3 fatty acids, paprika and marigold on physical properties of eggs. J. Process. Energy Agric. 2016, $20,58-62$. 